\title{
Resistance of endotracheal tubes measured after extubation in ICU patients
}

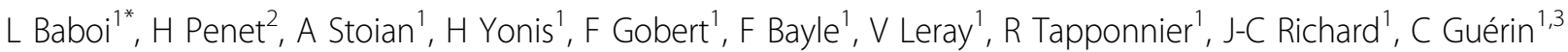 \\ From ESICM LIVES 2015 \\ Berlin, Germany. 3-7 October 2015
}

\section{Introduction}

Increase in resistance of endotracheal tube (RETT) during mechanical ventilation in ICU should reflect reduction in internal diameter due to accumulation of secretions.

\section{Objectives}

The aim of this study was to measure RETT after extubation in ICU patients. Our hypothesis was that RETT increased with the length of use of invasive mechanical ventilation.

\section{Methods}

The study was performed over patients intubated for at least 1 day in our ICU. Once the patient was extubated, tube was immediately stored in a plastic bag at room temperature and kept in a safe place until bench assessment. This was performed maximal 24 hours after extubation as follows. The endotracheal tube was attached to a filter (Hygrobac) and both were set to ASL 5000 active servo lung (IngMar medical). The lung model was set in passive condition in order to deliver two consecutive breaths at constant flow from 2 to $-2 \mathrm{~L} / \mathrm{s}$. The filter was tested first then the filter and the endotracheal tube were run. The relationship of pressure $(\mathrm{P})$ to flow was fitted to the following equation $\mathrm{P}=\mathrm{K}_{1}$ flow $+\mathrm{K}_{2}$ flow 2 the where $K_{1}$ and $K_{2}$ are constants. $P$ pertaining to endotracheal tube was obtained by subtracting $\mathrm{P}$ from filter to $\mathrm{P}$ from filter and endotracheal tube. Dividing $\mathrm{P}$ by flow led to RETT $=K_{1}+K_{2}$ flow. RETT at $1 \mathrm{~L} / \mathrm{s}(\mathrm{cm}$ $\mathrm{H} 2 \mathrm{O}$ ) was equal to $K_{1}+K_{2}$. The relationships of K1, K2 or RETT to lenght of intubation was analysed by linear mixed model where tube brand and size were factors with random effects.

${ }^{1}$ Hôpital de la Croix Rousse, Lyon, France

Full list of author information is available at the end of the article

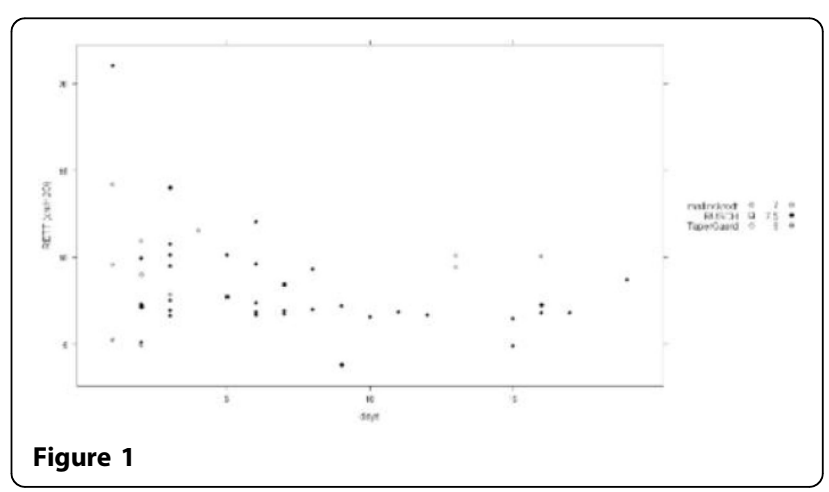

\section{Results}

We included 52 patients (34 male) of median (1st-3rd quartiles) age 68 (61-78) years. The median duration of intubation was 5.5 (2-9) days ( $\min 1-\max 19$ days). Endotracheal tubes were from Mallinckrodt $(n=45)$, TaperGuard $(\mathrm{n}=4)$ or Rush $(\mathrm{n}=3)$ brands and internal diameter $7.0(\mathrm{n}=10), 7.5(\mathrm{n}=39), 8.0(\mathrm{n}=3) \mathrm{mm}$. The relationships of K1, K2 or RETT to length of intubation were not significant taking into account both brand and size of endotracheal tubes (figure).

\section{Conclusions}

Increase in resistance of endotracheal tube used in the ICU is not related to the length of tracheal intubation.

\section{Authors' details \\ ${ }^{1}$ Hôpital de la Croix Rousse, Lyon, France. ${ }^{2}$ Ecole des Haute Etudes Ingenieur, Lille, France. ${ }^{3}$ INSERM UMR 955, Créteil, France.}

Published: 1 October 2015

doi:10.1186/2197-425X-3-S1-A385

Cite this article as: Baboi et al:: Resistance of endotracheal tubes measured after extubation in ICU patients. Intensive Care Medicine Experimental 2015 3(Suppl 1):A385. (c) 2015 Baboi et al.; This is an Open Access article distributed under the terms of the Creative Commons Attribution License (http:// creativecommons.org/licenses/by/4.0), which permits unrestricted use, distribution, and reproduction in any medium, provided the original work is properly cited. 